\title{
Health risk assessment along the wastewater and faecal sludge management and reuse chain of Kampala, Uganda: a visualization
}

Samuel Fuhrimann ${ }^{1,2}$, Mirko S. Winkler ${ }^{1,2}$, Pierre H.H. Schneeberger ${ }^{1,2,3,4}$, Charles B. Niwagaba ${ }^{5}$, Joseph Buwule ${ }^{6}$, Mohammed Babu , Kate Medlicott ${ }^{8}$, Jürg Utzinger ${ }^{1,2}$, Guéladio Cissé ${ }^{1,2}$

${ }^{1}$ Department of Epidemiology and Public Health, Swiss Tropical and Public Health Institute, Basel, Switzerland; ${ }^{2}$ University of Basel, Basel, Switzerland; ${ }^{3}$ Department of Epidemiology and Molecular Diagnostics, Agroscope Changins-Wädenswil ACW, Wädenswil, Switzerland; ${ }^{4}$ Department of Virology, Spiez Laboratory, Federal Office for Civil Protection, Spiez, Switzerland; ${ }^{5}$ Department of Civil and Environmental Engineering, Makerere University, Kampala, Uganda; ${ }^{6}$ Landmark Media Consultancy LTD, Kampala, Uganda; ${ }^{7}$ Department of Research and Development, National Water and Sewerage Corporation, Kampala, Uganda; ${ }^{8}$ Department of Public Health and Environment, World Health Organization, Geneva, Switzerland

\begin{abstract}
Reuse of wastewater in agriculture is a common feature in the developing world. While this strategy might contribute to the livelihood of farming communities, there are health risks associated with the management and reuse of wastewater and faecal sludge. We visualise here an assessment of health risks along the major wastewater channel in Kampala, Uganda. The visualization brings to bear the context of wastewater reuse activities in the Nakivubo wetlands and emphasises interconnections to disease transmission pathways. The contextual features are complemented with findings from environmental sampling and a cross-sectional epidemiological survey in selected exposure groups. Our documentation can serve as a case study for a step-by-step implementation of risk assessment and management as described in the World Health Organization's 2006 guidelines for the safe use of wastewater, greywater and excreta in light of the forthcoming sanitation safety planning approach.
\end{abstract}

Keywords: wastewater reuse, faecal sludge, sanitation safety planning, health risk assessment, visualization, Uganda.

Link: https://www.youtube.com/watch?v=CQEC3d4iE_A\&spfreload=10

\section{Background}

Reuse of wastewater and faecal sludge is commonly practised in many parts of the world, as it generates livelihood opportunities, especially in urban settings of low- and middle-income countries (Drechsel et al., 2010). However, direct or indirect contact to wastewater and faecal sludge is associated with microbial and chemical hazards, which frequently result in adverse health outcomes as mentioned in specific guidelines issued by the World Health Organization (WHO) (WHO, 2006). Indeed, various pathogenic

\footnotetext{
Corresponding author:

Guéladio Cissé

Department of Epidemiology and Public Health

Swiss Tropical and Public Health Institute

P.O. Box, CH-4002 Basel, Switzerland

Tel. +41 61 284-8304; Fax +41 61 284-8105

E-mail: gueladio.cisse@unibas.ch
}

bacterial and viral strains can cause ill-health, such as diarrhoea, respiratory tract infection and skin disease (WHO, 2006). Environmental contamination with helminth eggs and larvae (e.g. Ascaris lumbricoides, hookworm and Trichuris trichiura) and intestinal protozoa cysts and oocysts (e.g. Entamoeba histolytica and Giardia intestinalis) can lead to intestinal parasitic infections in animals and humans (Becker et al., 2013; Strunz et al., 2014). Toxic chemical compounds, such as heavy metals discharged in industrial effluents, can lead to chronic disease and cancer (Ackah et al., 2013).

Urbanisation continues at a rapid pace, particularly in low- and middle-income countries posing challenges for the sanitation infrastructure with regard to operation and maintenance of wastewater and faecal sludge treatment plants (Rydin et al., 2012). Rapidly growing cities, such as Kampala in Uganda, are characterised by aging, overloaded wastewater treatment facilities serving a small proportion of the population, which is coupled with limited faecal sludge collection and treat- 
ment from on-site facilities. This is a scenario the majority of the population commonly has to face in densely populated, unplanned, low-lying parts of such cities. As a result, water used for irrigation generally carries faecal and chemical contamination from a number of sources, including treatment plant effluent, leakage or illegal discharge of faecal sludge, industrial sewage and open defecation within catchments. Limiting this exposure requires a better understanding of the sources of contamination and barriers that can be applied at various stages (WHO and UNICEF, 2014). Achieving targeted levels of service for wastewater and faecal sludge collection and treatment is extremely challenging in the context of rapid growth and limited funding for capital investment, operation and maintenance. There is thus a need for risk assessment and management approaches to identify and mitigate health risks especially for the most vulnerable populations. This can be done by a combination of treatment and cost-effective non-treatment measures and by mobilising a wide group of stakeholders to implement and monitor such risk assessment approaches (WHO, 2006).

Recognising the growing use of wastewater and faecal sludge, WHO has published guidelines for the safe use of wastewater, excreta and greywater (i.e. water generated from washing food, clothes and dishware, as well as from bathing, but not from toilets) (WHO, 2006). These guidelines provide a detailed methodology on how to assess and mitigate health risks in connection with the reuse of wastewater, excreta and greywater in agriculture and aquaculture. An important feature of the guidelines is that health-based targets are set out (e.g. maximum contamination of Escherichia coli and helminth eggs in treated wastewater in relation to the reuse scheme) by employing a multiple barrier approach. For this purpose, a broad set of technical and non-technical control options are proposed that are tailored for the different stages of a reuse system. Health-based targets should be set at the national level and might be based on well-defined health metrics, e.g. $10^{-6}$ disability-adjusted life years (DALYs) per person per year. While the WHO guidelines are valuable, their practicability and uptake in low- and middle-income countries proved difficult (Mara et al., 2010).

Against this background, WHO initiated the development of a sanitation safety planning (SSP) manual with the aim of providing a simple, step-by-step guidance on how to use and apply these guidelines. The approach takes users through the process of risk assessment, management and monitoring that com- prises six distinct steps that include definition of the sanitation system, hazard identification and development of monitoring plans and supporting programmes. Importantly, the development of the SSP manual includes an extensive pre-testing phase in various settings across the world.

The motivation of the current visualization is to explain and feature the risk assessment and management concept covered by the SSP using the experience from Kampala as an example. The following questions guided the script:

(i) How can the rich evidence-base of the WHO guidelines be encapsulated in a simple and accessible format to trigger a step-by-step implementation of the SSP approach?

(ii) What are the lessons learned from validating the SSP approach in Kampala?

(iii) How can we visualise an in-depth assessment and mapping of health risks related to different exposure groups along the wastewater and faecal sludge reuse chain in the Nakivubo wetlands?

Our visualization is structured as follows. First, we provide a general introduction to the concepts and challenges of wastewater and faecal sludge management and reuse in low- and middle-income countries. Second, we demonstrate the application of risk assessment, management and monitoring as described in the WHO guidelines. Third, we show how our work and experience in Kampala can contribute to a step-bystep implementation of the six SSP steps.

The SSP validation in Kampala was focused on the major wastewater system in this city of 1.8 million people, the capital of Uganda, which is located on the northern shores of Lake Victoria at an altitude of $1,140 \mathrm{~m}$ above the mean sea level at latitude $0^{\circ} 18^{\prime} 49.18^{\prime \prime} \mathrm{N}$ and longitude $32^{\circ} 36^{\prime} 43.86 "$ E. Like the case in many African cities, Kampala's sewage system is constrained with less than $10 \%$ of the population currently covered. Hence, the large majority of the population relies on local sanitation facilities such as pit latrines and septic tanks. Open defecation is still commonly practiced (Uganda Bureau of Statistics, 2013). For the SSP manual validation, the wastewater chain was divided into four study areas: (i) the Nakivubo channel with its wastewater treatment plant "Bugolobi Sewage Treatment Works" (BSTW); (ii) the Nakivubo wetlands; (iii) community areas bordering the wetlands, which are often affected by flooding events; and (iv) the Inner Murchison Bay within Lake Victoria (Fig. 1). The Nakivubo channel is $12.3 \mathrm{~km}$ long and transports wastewater from the communities, markets, industries and the treated 

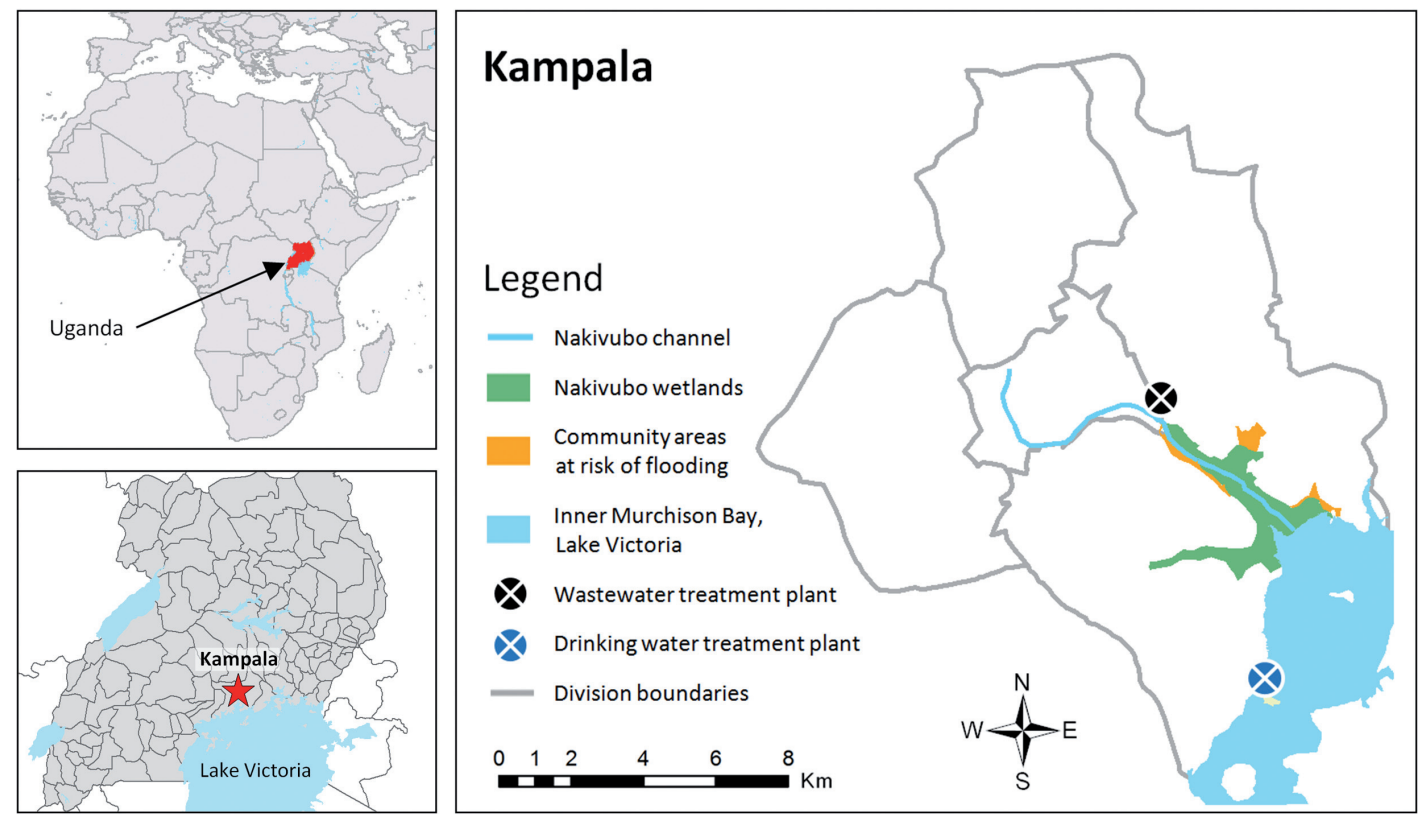

Fig. 1. Map of Kampala, the capital of Uganda, showing the study areas from the wastewater treatment to the drinking water treatment plant, highlighting the four specific study sites (Nakivubo channel, Nakivubo wetlands, community areas and the Inner Murchison Bay in Lake Victoria).

effluent of the BSTW. The final stretch of the channel comprises $4.5 \mathrm{~km}$ through the Nakivubo wetlands before reaching the Inner Murchison Bay within Lake Victoria. The Nakivubo wetlands cover approximately $5.3 \mathrm{~km}^{2}$ and have a total catchment area of approximately $40 \mathrm{~km}^{2}$. The whole wetland area is divided into a northern and a southern part separated by a railway. North of the railway is mainly drained farmland, while the South consists mainly of wetlands with floating "vegetational islands". Both areas are extensively cultivated with yams and sugar cane. Informal communities that are at highest risk of flooding events are situated along both sides of the wetlands (approximate population: 12,000 people). The Inner Murchison Bay also supplies Kampala with drinking water which is pumped and treated only 4 $\mathrm{km}$ away from the outlet of the Nakivubo channel. Moreover, the lake is economically important for fishery (Mbabazi et al., 2010).

The case study involved an in-depth characterisation of the wastewater and faecal sludge reuse system and specific risk assessments in different exposure groups. Since major data gaps on water- and soil-related diseases and chemical pollutants were identified, a crosssectional survey and an environmental sampling were carried out in late 2013. In short, a total of 915 participants were enrolled and stratified into five groups according to their exposure risk to wastewater: (i) wastewater treatment plant workers; (ii) faecal sludge collectors; (iii) farmers; (iv) exposed community mem- bers who are at risk of flooding; and (v) non-exposed community members who are not directly exposed to wastewater within the Nakivubo area. Particular emphasis was placed on intestinal parasitic infections, skin disease, eye disease and diarrhoea. The survey comprised two components: (i) a questionnaire study to obtain health risk and health outcomes related to the exposure to wastewater; and (ii) collection of stool samples to determine the prevalence and intensity of helminths using the Kato-Katz method (Katz et al., 1972) and intestinal protozoa infections using the formalin-ether concentration technique (Utzinger et al., 2010). For the environmental sampling, water, sediment, soil and plants were collected for 8 weeks in the rainy season from October to December 2013. A broad range of microbial and chemical pollutants were investigated, such as thermo-tolerant coliforms, E. coli, Salmonella spp., helminth eggs and heavy metals (cadmium, copper, iron, lead, chromium and zinc) to deepen the understanding of the contamination of different environments and hence, better characterise risk profiles of the different exposure groups.

Results from the cross-sectional survey revealed that, in terms of intestinal parasitic infections, farmers were at highest risk (prevalence of infection: $75.9 \%$ ), followed by exposed community members $(53.2 \%)$, non-exposed community members $(44.7 \%)$, wastewater treatment plant workers $(41.9 \%)$ and faecal sludge collectors $(35.8 \%)$. Our results from the environmental sampling showed that in water of the 
Nakivubo channel and the Nakivubo wetlands, mean concentrations of thermo-tolerant coliforms $\left(4.3 \times 10^{6}\right.$ and $10^{5}$ CUF/100 $\mathrm{ml}$, respectively) exceeded the national standards. Moreover, mean E. coli concentrations $\left(3.8 \times 10^{5}\right.$ and $9.9 \times 10^{4} \mathrm{CUF} / 100 \mathrm{ml}$, respectively) were in excess of thresholds put forth in the WHO guidelines for the safe use of wastewater in agriculture. A fifth of the water samples were found positive for hookworm eggs. Copper, iron and cadmium with 3.3, 21.5 and $0.14 \mathrm{ppm}$ in water, lead with $132.7 \mathrm{ppm}$ in soil and lead, cadmium and chromium in plant samples (yams 0.2, 4.0 and $4.4 \mathrm{ppm}$; sugar cane 0.2, 4.3, $8.4 \mathrm{ppm})$ were above international safety standards.

\section{Outlook}

We visualise a health risk assessment along a wastewater and faecal sludge management and reuse system in the context of a major East African city, reporting applications of risk assessment, management and monitoring along the sanitation chain as described in the 2006 WHO guidelines and the SSP manual. We believe that our contribution further underscores the value and potential of visualizing complex health issues in the form of a short video that is readily accessible by multiple stakeholders and local communities (Krieger et al., 2012; Winkler et al., 2012). Hence, our visualization can serve as a case study to be used as a part of the training material to facilitate SSP and support a step-by-step implementation of the WHO guidelines for the safe use of wastewater, excreta and greywater in agriculture and aquaculture in other cities across the developing world.

\section{Box 1. Overall aim.}

- A visual tool to characterise a major wastewater and faecal sludge management and reuse system in a major East African city context that could reach a broad range of stakeholders.

- An educational tool to facilitate sanitation safety planning and the step-wise implementation of the WHO guidelines on the safe use of wastewater, greywater and excreta reuse in agriculture and aquaculture.

Box 2. Applied software.

- Content visualization, including geospatial components: Microsoft Power Point 2013 (Microsoft Corporation; Edmond; WA, USA)

- Production of video for Internet streaming: Camtasia Studio 8 (TechSmith Corporation, Okemos, MI, USA)

- Three-dimensional fly-through visuals: Google Earth Pro (Google Earth Pro version 7.1.2.2041; Google, Inc., Mountain View, CA, USA)

\section{Acknowledgements}

Our special thanks go to the National Water and Sewerage Corporation, the Makerere School of Public Health and the Vector Control Division of the Ministry of Health in Uganda for support during data collection. We are grateful to project partners from the "Resource Recovery and Reuse project", namely: the International Water Management Institute (IWMI; Colombo, Sri Lanka), the World Health Organization (Geneva, Switzerland), the International Centre for Water Management Services (CEWAS; Willisau, Switzerland) and the Swiss Federal Institute of Aquatic Science and Technology (Eawag) - Department of Water and Sanitation in Developing Countries (Sandec; Dübendorf, Switzerland) for their valuable inputs along the studies. We are indebted to Amena Briët for her voice-over in the accompanying video. This study received financial support from the Swiss Agency for Development and Cooperation (SDC) and the "Deutsche Gesellschaft für Internationale Zusammenarbeit” (GIZ).

\section{Disclaimer}

Kate Medlicott is a staff member of the World Health Organization. The author alone is responsible for the views expressed in this paper and they do not necessarily represent the decisions, policy or views of the World Health Organization.

\section{References}

Ackah M, Anim AK, Gyamfi ET, Zakaria N, Hanson J, Tulasi D, Osei J, 2013. Uptake of heavy metals by some edible vegetables irrigated using wastewater: a preliminary study in Accra, Ghana. Environ Monit Assess 186, 621-634.

Becker SL, Vogt J, Knopp S, Panning M, Warhurst DC, Polman K, Marti H, von Müller L, Yansouni CP, Jacobs J et al., 2013. Persistent digestive disorders in the tropics: causative infectious pathogens and reference diagnostic tests. BMC Infect Dis $13,37$.

Drechsel P, Scott AC, Raschid-Sally L, Redwood M, Bahri A, 2010. Wastewater irrigation and health: assessing and mitigationg risk in low-income countries. London: Earthscan, 1-404 pp.

Katz N, Chaves A, Pellegrino J, 1972. A simple device for quantitative stool thick-smear technique in schistosomiasis mansoni. Rev Inst Med Trop São Paulo 14, 397-400.

Krieger GR, Bouchard MA, de Sa IM, Paris I, Balge Z, Williams D, Singer BH, Winkler MS, Utzinger J, 2012. Enhancing impact: visualization of an integrated impact assessment strategy. Geospat Health 6, 303-306.

Mara D, Hamilton A, Sleigh A, Karavarsamis N, 2010. Discussion paper: options for updating the 2006 WHO guidlines. Geneva: World Health Organization, 1-8 pp.

Mbabazi J, Kwetegyeka J, Ntale M, Wasswa J, 2010. 
Ineffectiveness of Nakivubo wetland in filtering out heavy metals from untreated Kampala urban effluent prior to discharge into Lake Victoria, Uganda. Afr J Agric Res 5, 34313439 .

Rydin Y, Bleahu A, Davies M, Dávila JD, Friel S, De Grandis G, Groce N, Hallal PC, Hamilton I, Howden-Chapman P et al., 2012. Shaping cities for health: complexity and the planning of urban environments in the $21^{\text {st }}$ century. Lancet 379, 2079-2108.

Strunz EC, Addiss DG, Stocks ME, Ogden S, Utzinger J, Freeman MC, 2014. Water, sanitation, hygiene and soil-transmitted helminth infection: a systematic review and meta-analysis. PLoS Med 11, e1001620.

Uganda Bureau of Statistics, 2013. 2013 statistical abstract. Kampala, Uganda.

Utzinger J, Botero-Kleiven S, Castelli F, Chiodini PL, Edwards
H, Köhler N, Gulletta M, Lebbad M, Manser M, Matthys B et al., 2010. Microscopic diagnosis of sodium acetate-acetic acidformalin-fixed stool samples for helminths and intestinal protozoa: a comparison among European reference laboratories. Clin Microbiol Infect 16, 267-273.

WHO, 2006. WHO guidelines for the safe use of wastewater, excreta and greywater. Volume I-IV, Geneva: World Health Organization.

WHO and UNICEF, 2014. Progress on drinking water and sanitation - 2014 update. Geneva: World Health Organization and UNICEF.

Winkler MS, Krieger GR, Divall MJ, Singer BH, Utzinger J, 2012. Health impact assessment of industrial development projects: a spatio-temporal visualization. Geospat Health 6, 299-301. 